\title{
The Japan Endocrine Society (JES)
}

85 Years of Quest for the Principles and Dedication to Basic and Clinical Endocrinology

The Japan Endocrine Society was founded in 1925 by Professor Kanji Tsuji of Kyoto University, making it the world second oldest just after the Endocrine Society in the United States founded 1922 (Figure 1). The official journal of the Japan Endocrine Society was published in 1925 (Figure 2), followed by the first annual scientific meeting in 1927. Professor Tsuji, during his study in the United Kingdom, was strongly inspired by the rapid rise of endocrinology, especially by the pioneering work by Sir Edward A. Schaefer of "internal secretion" and by the concept of "hormones" coined by Ernest H. Starling. The foresight of Professor Tsuji has been proved by the great scientific and clinical achievements by the society members and by 7,000 members the society boasts today. The Japan Endocrine Society is now one of the world-largest in the field.

It should be emphasized here that the Japanese scientists and clinicians have greatly contributed to the advances in modern endocrinology. Dr. Jyokichi Takamine, a chemist who was born towards the end of Edo era, succeeded in crystallizing adrenalin in 1901 (Figure 3). He is the first scientist ever worldwide to have successfully purified, synthesized and clinically applied a hormone for medical care. The case has been followed by many examples including the

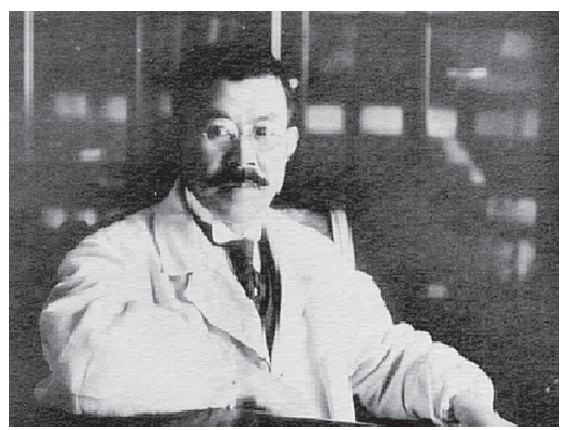

Figure 1

Prof. Kanji Tsuji (photographed in 1924)

Founder of the Japan Endocrine Society
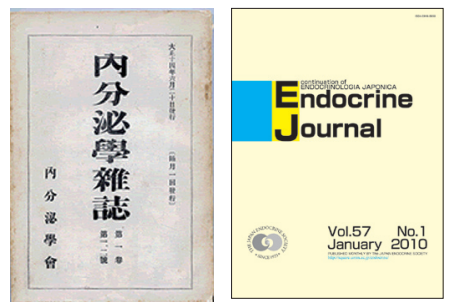

Figure 2

First Issues of Official Journals of the Japan Endocrine Society The Japanese Journal: "NaibunpigakuZasshi" i.e. Folia Endocrinologica Japonica The English Journal: Endocrine Journal

treatment of hypothyroidism by thyroid hormone and the treatment of diabetes by insulin. The discovery of adrenaline also led to a zealous search for synthetic agonists and antagonists that mimic or interfere with the effect of adrenalin. An example of outstanding Japanese clinical endocrinologists is Dr. Hakaru Hashimoto (Figure 4). As a surgeon in Kyushu University, he discovered and precisely described the clinical and histopathological features of chronic thyroiditis in 1912, now well known as Hashimoto's thyroiditis.

More recently, Dr. Hisayuki Matsuo and Dr. Kenji Kangawa discovered dozens of endogenous bioactive peptides including natriuretic peptide family (ANP, BNP, CNP) and ghrelin. With vigorous efforts and excellent collaboration, Professors Hiroo Imura and Kazuwa Nakao succeeded in the clinical application of ANP and BNP both as diagnostic methods and therapeutic drugs for heart failure in the 1990s, making them excellent examples of "Translational Research" in endocrinology and opened up a new field named "Cardiovascular Endocrinology and Metabolism." Making full use of the molecular cloning techniques, Professors Shousaku Numa and Shigetada Nakanishi were the first in cloning hormone precursor cDNAs including proopiomelanocortin, proenkephalin A and

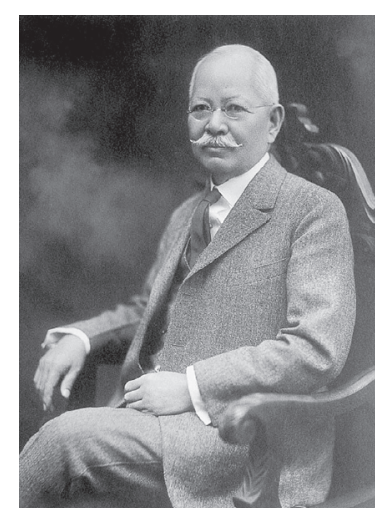

Figure 3

Dr. Jyokichi Takamine Purification of Adrenalin

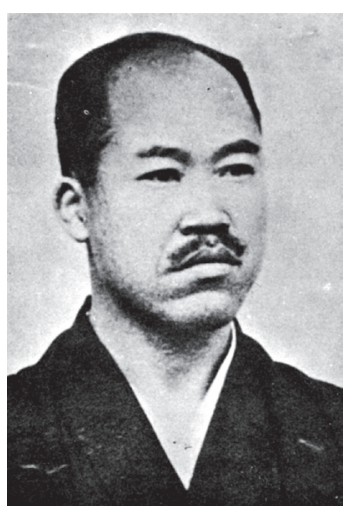

Figure 4 Dr. Hakaru Hashimoto Discovery of Hashimoto's thyroiditis 
proenkephalin B. Hormones secreted from classical and novel endocrine organs including cardiovascular organs and the adipose tissue act on various target tissues and raise a broad spectrum of cellular responses. Professor Yasumi Nishizuka identified protein kinase C signal transduction pathway, providing a firm basis for the study of second messengers and signalingrelated disorders.

The Japan Endocrine Society has also been at the forefront of international efforts for cooperation. In 1988, the Japan Endocrine Society hosted the $8^{\text {th }}$ International Congress of Endocrinology in Kyoto, which was the first time the congress was held in Asia (Figure 5). Today there are six related societies in the Japan Endocrine Society: Japan Thyroid Association, Japan Neuroendocrine Society, Japan Society of Reproductive Endocrinology, Japan Steroid Hormone Society, The Society of Cardiovascular Endocrinology and Metabolism, and Japan Endocrine Pathology Society. These societies, in close cooperation with the Japan Endocrine Society, provide a forum for the members to freely and actively share basic ideas, research outcomes and clinical cases. The Society particularly gives priority for the encouragement of young members and students (Figure 6).
The Japan Endocrine Society is quite unique in that its members are comprised of basic scientists, clinician-scientists and clinicians. The composition of these members provides a challenging opportunity to interact with each other, enabling the Society to contribute to the conceptual advances in physiology as well as medicine. Furthermore, the clinician members are from a variety of subspecialties, including internal medicine, surgery, neurosurgery, pediatrics, obstetrics, gynecology, urology etc. The diversity of the Society has always been the source of energy that has long vitalized scientific and clinical activities of the members and the Society alike.

After 85 years of legacy and at the dawn of the new era of biomedical sciences, the Japan Endocrine Society is now beginning to play a more active role on the global stage. By integrating rather than subdividing the research fields, the Society will continue to strike a novel concept, discover unknown factors and their functions, and investigate the mechanisms of the signal transduction. Through these activities and with firm determination, the Japan Endocrine Society will support the development of novel diagnostic and therapeutic techniques and contribute globally to the health of mankind.

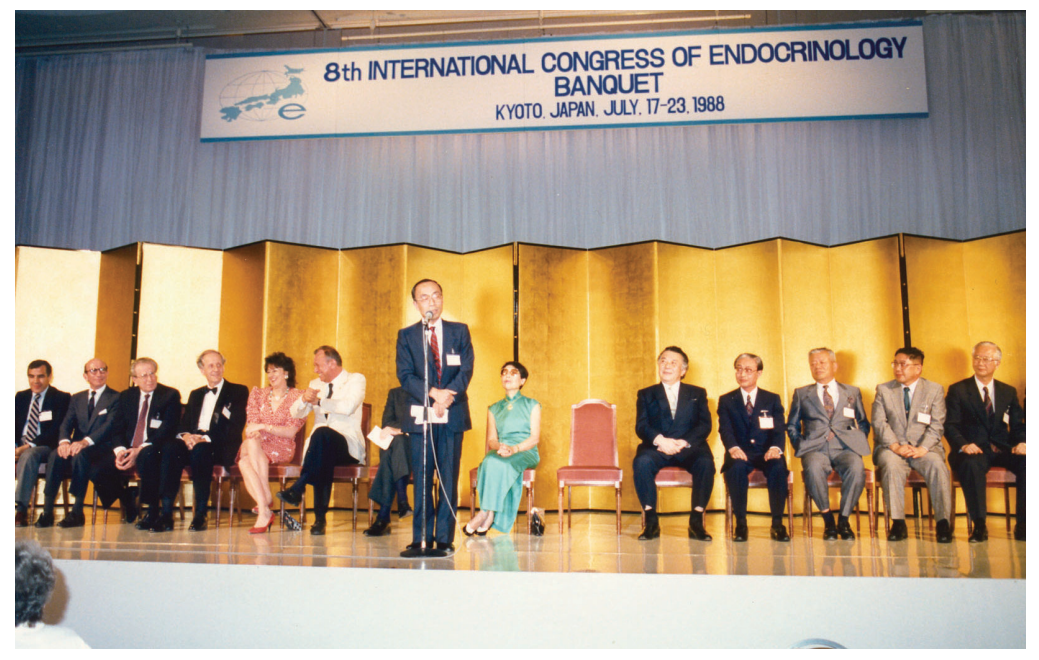

Figure 5

The $8^{\text {th }}$ International Congress of Endocrinology, Kyoto, Japan, 1988

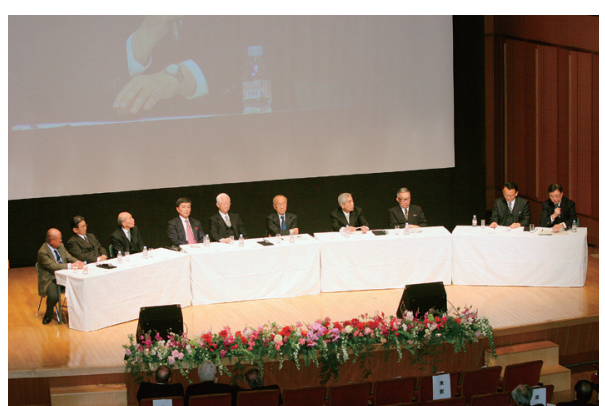

Figure 6

The $80^{\text {th }}$ Anniversary Ceremony and Lectures of The Japan Endocrine Society 